\title{
INTENSIFICATION OF FERMENTATION OF SEMI-FINISHED PRODUCTS OF HARDTRACKS WITH LOWERED SUGAR CONTENT
}

\author{
Kateryna lorgachova, Olga Makarova, Kateryna Khvostenko, \\ Anastasia Fateeva \\ Odessa National Academy of Food Technology, Ukraine \\ Kanatnaya Str. 112, Odessa 65039, Ukraine \\ phone: +380487253284 , mobile: +380958937043 \\ e-mail: epinchuk@ukr.net
}

\begin{abstract}
The article shows the appropriate of the development of pastry with lowered sugar content. An effective solution of this task is to replace sugar in their recipe with slowly digestible carbohydrates and dietary fiber, namely inulin-containing raw materials - Jerusalem artichoke powder. It was noted that the exclusion of sugar from the recipe of yeast pastry - hardtacks - leads to a deterioration of the products quality. It is proposed to use flour from waxy wheat to solve this problem, which is characterized by lack of amylose in the starch. It causes a significant difference in the technological properties of the waxy wheat flour. The expediency of joint use of proposed ingredients in the technology of hardtacks is investigated. Two methods of inulin-containing raw materials adding are proposed - in an sourdough or in equal parts in an sourdough and dough. It is found that the stepwise adding of Jerusalem artichoke powder contributes to obtaining a dough with a more loosened structure. The joint use of waxy wheat flour and Jerusalem artichoke powder, even in the case of the exclusion of sugar from the recipe, leads to the intensification of fermentation of semi-finished products for hardtacks, which allow to reduce the time of dough fermentation for hardtacks.
\end{abstract}

Keywords: waxy wheat, hardtacks, fermentation, sugar, Jerusalem artichoke powder.

\section{INTRODUCTION}

In process of development of new type of pastry actual trends are search and use of recipe ingredients, which allow to reduce the sugar content and energy value of this products. This tendency is caused by the growing demand for food products with functional and dietary properties on the background of increasing consumer awareness of the need to adhere to the principles of rational nutrition, as well as increasing the number of people with carbohydrate metabolism disorders - diabetes, obesity and etc .

The effective solution of this problem is the replacement of fast-digesting carbohydrates to slow-digesting carbohydrates, food fiber in pastry recipes, the consumption of which contributes to the reduction of carbohydrate load on the human organism. The particular interest as the ingredients that can be used to replace fast-digesting carbohydrates, is an inulin-containing raw material - a powder of Jerusalem artichoke (PJA). Along with the positive effect on the human organism due to its physiological properties, inulin is characterized by a number of technological advantages, which contribute to the increasing use of this raw material in various areas of the food industry, including the flour products production. 


\section{METHODS}

The quality parameters of semi-finished products during the fermentation were studied by generally accepted methods in Ukraine.

The acid accumulation was evaluated on the basis of change of its total titratable acidity (TTA). It was defined as the amount of $0,1 \mathrm{~N} \mathrm{NaOH}$ solution $(\mathrm{mL})$ used to neutralize $5 \mathrm{~g}$ sample weight homogenized with $50 \mathrm{ml}$ of distilled water. These analysis were carried out every 30 min during all term of fermentation (150 min). The gas (carbon dioxide) production during fermentation was evaluated by volumetric method under conditions of constant pressure and temperature. To make experimental determination of lifting force of yeast semifinished products we used the method, which is based on determining the floating speed of a ball of $10 \mathrm{~g}$ sample weight on the water. Lifting force is characterized by the time (minutes) from the moment when the ball is lowered in the water $\left(32^{\circ} \mathrm{C}\right)$ until the moment it floats on the surface of the water.

\section{EXPERIMENTAL AND RESULTS}

Dietary hardtacks "Arktika", which contain a small amount of sugar and fat, are selected, as an object of a study, for researching of products with reduced sugar content and caloricity. It is important to note that sugar, as a recipe ingredient, not only determines the taste of the product, but also effects on the alcoholic fermentation activity of yeast semi-finished products. Adding 2,5 to 3,0 \% of it is accompanied by an increase of amount of carbohydrate in the liquid phase of the dough, which are necessary for the nutrition of yeast cells. In connection with this, the complete absence of sugar in the recipe leads to a decrease of the fermentation intensity of semi-finished products based on bread wheat flour (BWF) and, as a consequence, to a deterioration in the product quality.

Special attention should be given to studying the effect of replacement sugar with PJA in the recipe of hardtacks on the process of fermentation of the semi-finished products. This is due to a significant effect of sugar on the formation of the porous structure of products from the yeast dough, and also it provides the accumulation of substances that cause their high organoleptic properties. To stabilize the quality of pastry with reduced sugar content, the use of waxy wheat flour (WWF), which is characterized by the absence of amylose in the starch, a large number of damaged starch granules, and also a high gas production in comparison with BWF, is suggested [1].

In research WWF of the Sofiyka variety wheat of domestic breeding was used, the technological properties of which differed significantly from the BWF [2]. To justify the recommended stage of WWF adding in hardtacks production we have suggested two methods: according to the traditional technology - adding the WWF at sourdough kneading stage (method 1), and adding the WWF in equal parts at sourdough and dough kneading stages (method 2).

The use of WWF in the hardtacks production with inulin-containing raw materials, despite the absence of sugar in the recipe, leads to an intensification of gas (carbon dioxide) production during the fermentation of semi-finished products. Probably, the obtained results is explained by the availability of most of its starch granules to the action of amylolytic enzymes and, as a consequence, by the higher WWF's gas-production ability compared with BWF. The analysis of the effect of the PJA method of adding shows that the sourdough, which contain whole amount of sugar substitute (1st method) in its composition, is characterized by more intensive carbon dioxide production during the fermentation. Its adding in equal parts to the sourdough and dough (2nd method) contributes to a greater increase in gassing in the dough both in comparison with the control, and with the dough, which is kneaded according to the

IRTIIE Vol. 5, No. 4, 2017 ISSN 1314-8788 (print), ISSN 1314-8796 (online), doi: 10.15547/artte.2017.04.010 


\section{ART'TlE $Y$}

Ipplied Resseirlohes in Technics, Technologies and Eductition

Journal of the Faculty of Technics and Technologies, Trakia University https://sites.google.com/a/trakia-uni.bg/artte/

1st method. Less intensive gas production in the dough, the technology of which envisages the adding of the WWF at sourdough kneading stage (method 1) is probably due to the fact that the main part of the sugars, introduced in semi-finished products with the PJA, are fermented at the first stage of dough preparation - in sourdough, and their quantity is insufficient to provide intensive gas production in the yeast dough. An adding of inulincontaining raw materials at the stage of kneading of the dough according to the second method provides an increasing of the amount of sugars necessary to ensure the vital activity of yeast cells.

During the ripening of yeast flour semi-finished products, along with alcoholic fermentation, the process of lactic acid fermentation takes place, which provides acid accumulation in yeast semi-finished products. Obtained, that the samples, containing WWF and PJA, have highest value of the final acidity. This is due to the positive effect of the products of yeast metabolism on the growth development of lactic acid bacteria, which accumulate in semifinished products of hardtacks to a greater extent, caused by the intensification of fermentation of samples based on non-amylose wheat flour. Also inulin-containing raw materials have a positive effect on the activity of acid-forming microorganisms due to the presence of carbohydrates, minerals and vitamins in their composition, which are an additional source of nutrition for them.

Lifting force, along with acid accumulation, is one of the most important technological characteristics, indicating the ripening of yeast semi-finished products (Table 1).

Table 1. Lifting force of hardtacks dough $(n=5, P \leq 0,05)$

\begin{tabular}{|l|c|c|c|c|c|c|}
\hline \multirow{2}{*}{$\begin{array}{l}\text { The duration of } \\
\text { fermentation, min }\end{array}$} & \multicolumn{7}{|c|}{$\begin{array}{c}\text { Lifting force, } \\
\text { min }\end{array}$} \\
\cline { 2 - 7 } & \multicolumn{2}{|c|}{ BWF+sugar } & \multicolumn{2}{c|}{ BWF+PJA } & \multicolumn{2}{c|}{ WWF+PJA } \\
\cline { 2 - 7 } & $1 \mathrm{~m}$ & $2 \mathrm{~m}$ & $1 \mathrm{~m}$ & $2 \mathrm{~m}$ & $1 \mathrm{~m}$ & $2 \mathrm{~m}$ \\
\hline 0 & 20 & 22 & 18 & 19 & 17 & 16 \\
\hline 30 & 16 & 18 & 14 & 16 & 13 & 14 \\
\hline 60 & 14 & 13 & 13 & 12 & 11 & 10 \\
\hline 90 & 12 & 11 & 11 & 10 & 9 & 8 \\
\hline 120 & 11 & 9 & 9 & 8 & 7 & 6 \\
\hline 150 & 10 & 8 & 8 & 7 & 6 & 5 \\
\hline
\end{tabular}

It was found that replacing sugar with PJA in a dough based on WWF caused to the reduction of the ball floating time by $1.6 \ldots 2$ times comparing to the control, depending on the method of the inulin-containing raw materials adding. This is obviously explained by the fact that using of WWF instead of BWF in recipe of yeast semi-finished products leads to the increasing of the mass fraction of available sugars for fermentation and the amount of nutrients, which activate the vital functions of yeast. Also, the PJA contains a large amount of inulin, which are hydrolyzed by the inulaza enzyme. Due to this the fructose and a number of other products of inulin's decomposition with various degrees of polymerization are formed [4]. Formation of these products, which are an additional source of carbohydrates, cause to the intensification of the carbon dioxide production and lead to the decrease of the density of semi-finished products due to the formation of a more porous structure. Based on the obtained results, we recommend to reduce the time of fermentation of the dough based on non-amylose wheat flour for $30 \ldots 60$ minutes, depending on the method of adding PJA, in the technology of low sugar hardtacks. 


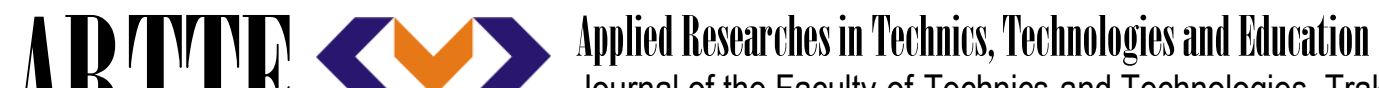 Journal of the Faculty of Technics and Technologies, Trakia University https://sites.google.com/a/trakia-uni.bg/artte/}

\section{CONCLUSIONS}

Thus, based on the results of the research, it can be concluded that the replacement of bread wheat flour for the waxy wheat flour with the use of inulin-containing raw materials, even in the case of the absence of sugar in the recipe, leads to the intensification of semifinished products fermentation for hardtacks. This is evidenced by an increase of carbon dioxide production, titratable acidity and lifting force of these samples compared to the control. For a more complete justification of recommendations for the adding of inulincontaining raw materials in the production of hardtacks with reduced sugar content, it is necessary to research of joint effect of flour from waxy wheat and Jerusalem artichoke powder on the quality of products.

\section{REFERENCES}

[1] Blake L.H., Jenner C.F., Barber A.R. (2015). Effect of waxy flour blends on dough rheology and bread quality. Food science+technology, Vol 50, No 4, (2015), pp. 926933.

[2] Iorgachova K.G., Makarova O.V., Khvostenko K.V., Rybalka O.I. (2012). Determination of the technological properties of the flour of non-amylose wheat by the characteristics of the carbohydrate-amylase complex. Food science and technology, No 1, (2012), pp. 3740.

[3] Kuznetsova L.S., Sidanova M.U. (2008). The technology of pastry production. Academy, Moscow, (2008).

[4] Medicinal plant Jerusalem artichoke. [Online]. Available: http://www.malvatopinambur.com/. 